\title{
When is a Syllable not a Syllable?*
}

\author{
Mary E. Beckman \\ mbeckman@ling.ohio-state.edu
}

\begin{abstract}
This paper reviews evidence for unifying two seemingly disparate types of syllable reduction phenomena: the elision of reduced vowels in English and German, and the devocalization of high vowels in Japanese, Korean, and Montreal French. Both types of "casual speech rule" can be understood as extreme endpoints of a phonetic continuum of gestural overlap. The vowel is seemingly deleted or devoiced when the gestures of neighboring consonants encroach so completely into the space for the affected vowel that the relevant vowel gesture(s) leave no salient acoustic trace. However, in some cases in some of these languages, the reduction has been phonologically reanalyzed, so that the word loses a syllable. The paper explores the circumstances under which such reanalysis can occur.
\end{abstract}

\section{Introduction}

Recent work on the gestural organization of speech (e.g., Browman \& Goldstein $1990 \mathrm{a}, 19.90 \mathrm{~b}$ ) supports alternative phonetic accounts of such segmental reduction phenomena as the devoicing of high vowels in Japanese and Korean and the deletion of schwa and simplification of consonant clusters in English and.German. Whereas earlier phonological descriptions assumed these to be categorical changes of phonological form, akin to the alternations seen in the inflectional morphology of the same languages, we now can describe them as byproducts of subtle shifts in the articulatory specifications of gestural magnitude and timing - shifts which can cause dramatic changes in the acoustic realization of a particular segmental string because of nonlinearities in the mapping between the two phonetic representations. For example, in fast-speech productions of German mit dem Wagen [mit ${ }^{\mathrm{b}}$ dom v'a:gən] 'by car', the temporal distance between the oral gestures for the consonants [d] and [m] in dem and between those for [g] and [n] in Wagen might be reduced to the point of aerodynamically hiding the release of the alveolar or velar stop, thus effectively deleting the unstressed vowels, as in [mith ${ }^{\mathrm{d}} \mathrm{m}$ v'a:gn] (Kohler 1990). The devoicing of the first [ur] in Japanese/supootu/ [su po:tsul] 'sports' might be

*This paper was originally presented at the Dokkyo International Forum on Speech Recognition and Phonology, Dokkyo University, Soka City, Saitama Prefecture, Japan, 18-19 December 1993, and will appear in the annual report of the Dokkyo University International Center. As the many citations of "personal communication" suggest, I am indebted to Louise Levac for sharing with me her intuitions as a native speaker of Montreal French after her talk at the ESCA Workshop on Prosody in Lund in September 1993, and to Stefanie Jannedy for her extreme generosity with her as yet unpublished data and her astute observations of her native language. The analysis of Korean vowel devoicing owes to Sun-Ah Jun much more than is suggested by the simple reference to Jun \& Beckman (1993). I thank Beth Hume, Mariko Kondo, Kikuo Maekawa, and Amold Zwicky for giving me copies of several papers to which I otherwise would not have had access. 
described as a similar hiding of the vowel's oral and glottal gestures by those of the preceding fricative (Jun \& Beckman 1993).

From the point of view of segmental production and perception, these reduction phenomena are strikingly similar across languages. The acoustic consequence of gestural overlap between the first consonant and vowel in /supootu/ is virtually indistinguishable from the consequence of extreme gestural overlap in English supports; both result in something that English speakers readily perceive as an initial [sp] cluster. However, the prosodic consequences of these segmental reductions can be strikingly different. In Japanese, the syllable count is necessarily preserved even under such complete reduction that no acoustic trace of vowel formants remain, and /supootu/ will always have three syllables, no matter whether the first vowel is devoiced or not. In English, by contrast, the comparable reduction of an unstressed vowel can in effect delete the syllable, so that the disyllable supports can be confused with the monosyllable sports. These different consequences highlight the cognitive robustness of such prosodic units as the syllable, and the very different roles that such units play in speech rhythms across languages.

This paper will survey the phonological circumstances under which syllable count can change as a result of extreme vowel reduction. Since a thorough review of all languages in which such reduction phenomena have been observed would be impossible, the bulk of the discussion will be limited to only five languages, with a view to representing a wide range of rhythmic types - mora-timed Japanese, syllable-timed French and Korean, and stress-timed English and German. The paper will begin by describing the phonetics of vowel reduction in more detail, reviewing some of the evidence in the literature supporting the newer phonetic accounts of the phenomenon which differentiates it from phonological processes that yield superficially similar altemations.

\section{Deletion of $/ a /$ in English and German}

In English and German, the prosodically weakest syllables - i.e., unstressed syllables with an underlying / $/ \mathrm{d} / \mathrm{vowel}$ - often undergo even further reduction, to the point of effectively losing any salient phonetic trace of the vocalic nucleus. Table 1 illustrates the segmental conditions conducive to this effect, without differentiating among the varying speech rates or styles where some of these are likely to occur (e.g., [''ofli] for awfully is readily available even in more careful, formal speech contexts where $\left[\mathrm{k}^{\mathrm{h}} \mathrm{wSpm}^{\mathrm{S}}\right]$ for captain would be produced only as a deliberate rusticism). In both languages, the $/ \partial /$ is very likely to be "deleted" in this way when it is flanked either by an obstruent and a sonorant or by an obstruent and a sibilant fricative. In medial syllables, this segmental context allows an apparent heterosyllabic consonant cluster to result. In initial or final syllables, the sonorant or fricative consonant apparently replaces the vowel as the syllabic nucleus. In German, it is not uncommon also to "delete" the vowel between two sonorants, a context where English is more likely to retain some acoustic remnant of the underlying vowel (as can be seen by comparing the speech rates or styles in which the pronunciations given in the table for Kannen and linen are likely). The last block of the table illustrates that the phenomenon is not necessarily limited to underlying $/ a /$, but can apply to other lax vowels in comparably weak prosodic position.

Superficially, these alternations between forms with and without a vowel resemble morphological alternations such as the variants of the regular possessive form in English (e.g., Pat's/pæts/, Bob's / babz/, horse's /h's.ssiz/, but Horace's /h'orosiz/ $\sim$ Horace' /h'oras/, Achilles's /ak'1lizız/ Achilles' /ak'rliz/). And that is how they are treated in many earlier descriptions of them. For example, Zwicky 
(1972) describes the pronunciations listed in Table 1 for English words such as mystery and happening in terms of "Slur", a phonological rule that deletes the reduced vowel (i.e., $[\ni] \rightarrow \emptyset$ ) between any consonant and an unstressed syllable beginning with $[\mathrm{s}],[1]$, or [n]. ${ }^{1}$ Strauss (1982) similarly describes German as having optional phonological rules of reduction to schwa and schwa deletion to account both for the weak forms of function words, such as [dam] [dm] for dem [de:m] cited above, and for casual-speech productions of content words such as [Ya:d1] for Adel and [1artn] for leiten. Hall (1992) differentiates these two types by describing the latter set of pronuciations as the result of the non-application of an optional "Schwa-Default Rule" in his schwa-epenthesis account of forms such as [Sa:dl] and [1artq], but nonetheless makes them both categorical phonological processes.

Table 1. Schwa-deletion (and unstressed $/ \mathrm{z} /$ - or $/ \varepsilon /$-deletion) in English and German.

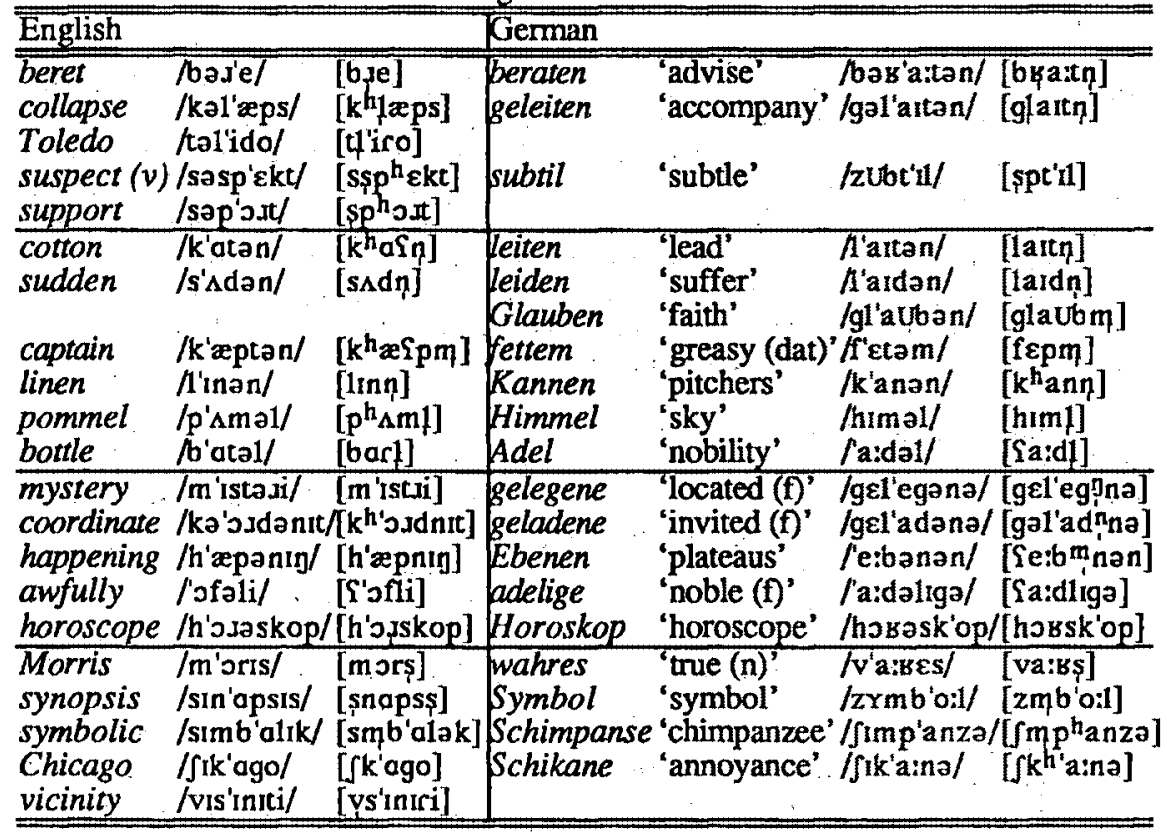

Kohler (1990), by contrast, argues against all such traditionally generative phonological accounts. If it is described by symbolic rules of the sort posited by Strauss (1982) and Hall (1992), the apparent deletion of the unstressed vowel in weak forms of monosyllabic function words and in various other weak syllables in

1"Slur" is a separate rule from the "Pre-stress Contraction" that Zwicky posits for forms such as [vs'iniri] for vicinity and [ $\mathrm{k}^{h_{1}}$ ps] for collapse. For the latter set of forms, he considers that they may be "merely automatic consequences of faster speech", although he points out that such an account "presumes a coherent and detailed theory of linguistic phonetics, which [in 1972] cannot be said to be available yet" [Zwicky 1972, p. 278]. 
German is difficult to relate to the consonant assimilations and substitutions that tend to coöccur with the schwa deletion in connected or casual speech. For example, the phrase mit dem Wagen 'by car' might be realized as any of the segment strings in Table 2, showing the output at each step in the application of possible rules in a text-to-speech system. These rules can be grouped into sets for progressively more casual stylistic modules. However, while it might be useful for text-to-speech synthesis systems to discretize the stylistic progression in this way, such rule modules cannot provide an explanatory account of what speakers are actually doing in producing the apparent progression of forms transcribed in the table. On the other hand, if each closely related set of transcribed feature changes is instead understood as the acoustic byproduct of some articulatory restructuring in the interest of "motor economy", the seemingly disparate changes that tend to coöccur within a "rule module" can be explained and predicted in terms of the phonetic process involved. For example, when stated in terms of phonological rules, the progression from [gan] to [gg] involves two discrete and formally unrelated changes: schwa deletion and nasal place assimilation. When understood as a phonetic reorganization, however, it might be stated as a single articulatory change: letting the gesture for the dorso-velar constriction extend well into the vowel so that the magnitude of its releasing phase is drastically reduced could simultaneously "delete" the [ə] and aerodynamically "hide" any more anterior apical constriction gesture. Kohler describes many other similar examples in support of the idea that formulating a precise phonetic model of articulatory timing and gestural magnitude could unify schwa deletion with the stylistically related consonant assimilations and weakenings.

Table 2. Realizations of mit dem Wagen 'by car' after the application of each applicable casual-speech rule in a German text-to-speech system. (Kohler, 1990.)

\begin{tabular}{|c|c|}
\hline 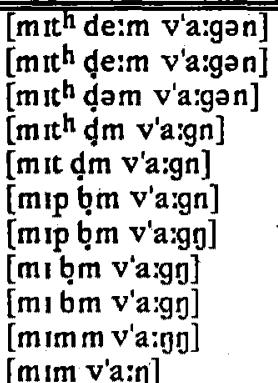 & $\begin{array}{l}\text { input form } \\
\text { devoicing of voiced stops after voiceless consonants } \\
\text { vowel reduction in weak form of function word } \\
\text { schwa deletion before nasals after stressed syllable } \\
\text { deaspiration of voiceless stops before stops and nasals } \\
\text { regressive place assimilation of apical nasals and stops } \\
\text { progressive place assimilation of apical nasals and stops } \\
\text { degemination of devoiced or voiceless consonants } \\
\text { voicing of plosives in unstressed function words } \\
\text { regressive nasal assimilation of voiced stops } \\
\text { degemination of other consonants }\end{array}$ \\
\hline
\end{tabular}

Browman and Goldstein (1990a, 1990b) propose such a phonetic model. The "gestural score" represents an utterance as a set of discrete dynamically-specified control regimes for accomplishing such basic tasks as forming a constriction somewhere in the vocal tract. These control regimes (or "gestures") are temporally coördinated within and across parallel channels, with each channel (or "tier") allocated to the control of a different articulatory subsystem. Thus, for example, the initial /bar/ sequence in the English word beret is represented in the score as a set of labial-closing and rounding gestures on the lip tier, an apico-postalveolar approximation gesture on the tongue-tip tier, and so on. The approximation gesture on the tongue-tip tier can be timed to overlap somewhat with the labial-closing and releasing gesture on the lip tier. The audible presence or apparent deletion of the [a] can be modelled simply by changing the degree of overlap between the constriction gestures on the two tiers. Indeed, because the gestural-score representation has been implemented as the front end to an articulatory synthesis system, Browman 
and Goldstein (1990b) could generate a continuum of degrees of gestural overlap in a series of stimuli which they presented to listeners for identification. The identification function shows a category shift, with subjects perceiving beret for the stimuli with least overlap, but bray for the stimuli with greatest overlap. This result is in keeping with Price's (1980) earlier study showing that the difference between parade and prayed or polite and plight can be synthesized by varying such things as the resonant consonant's duration and amplitude in ways that mimic the acoustic results of varying gestural overlap.

The generalization from such results to the representation of actual fast-speech productions is suggested already in Browman and Goldstein's (1990a) seminal paper on the gestural score. If the apparent deletion of the vowel nucleus and neutralization with the corresponding consonant cluster is demonstrably nothing more than the extreme endpoint of an attested continuum of degrees of reduction and confusability, then the continuously variable values of overlap in the gestural score is a better representation than a categorical phonological rule of schwa deletion for fast-speech pronunciations of words such as parade, support, sudden, and happening. Further support for this idea comes from data in Manuel et al. (1992), who document subtle acoustic cues suggestive of an underlying "hidden" glottal-adduction gesture in support even in tokens that could be transcribed as [spost] and misperceived as sport (see also Fokes \& Bond, 1993).

Jannedy (1993) gives evidence for an analogous gestural overlap account for apparent schwa deletion in German. She had northern German subjects produce a paragraph in which were embedded, in segmentally and prosodically similar contexts, words from minimal pairs such as braten (/bs'atan/ 'fry') versus beraten (/bak'atan/ 'advise') and Kannen (k'anon/ 'pitchers') versus kann (/kan/ 'be able to'). She had the subjects read the paragraph ten times, starting first at a comfortable "neutral". rate and then producing four repetitions in progressively faster versions, then returning to neutral rate to produce a series of five more repetitions at progressively slower tempi. She then excised the target words from context and presented them to native speakers for identification in a forced-choice judgment. Her results for Kannen versus kann, are particularly illuminating. Plotting the duration of the target/non/ in Kannen or /n/ in kann against the duration of the remaining $/ \mathrm{ka} /$ in the production of kann (used as a metric of the overall speech rate), she found that the two regression functions converged at the fastest rates. Moreover there was a comparable convergence in the identification functions: at faster and faster rates, more and more of the listeners misjudged Kannen to be kann. For beraten versus braten, there was less convergence in the regression lines for the production data, but as much in the perception data, albeit in the other direction: listeners often misjudged braten to be beraten at the slower rates. Moreover, in no case was there evidence of a bimodal distribution in the duration or identification measures - thus, no evidence of a categorical shift from presence to absence (or from absence to presence) of a reduced vowel phone. Jannedy concludes that German has neither a schwa-deletion rule, as proposed by Strauss (1982), nor a schwa-insertion rule, as proposed by Hall (1992). That is; the apparent alternation between forms with and forms without schwa is an artificial imposition of two symbolic categories onto a continuum of degrees of encroachment by the neighboring consonants' gestures onto those of the vowel.

\section{3. "Devocalization" of high vowels in Japanese, Korean, and Montreal French}

Jun and Beckman (1993) propose a comparable gestural-overlap representation for another common reduction phenomenon involving the devoicing or deletion of high vowels. Such devocalization has been studied most extensively for standard (Tokyo) Japanese, but it also occurs in the Montreal variety of French and in at least 
the standard (Seoul) and Chonnam dialects of Korean. Table 3 gives some transcribed examples from Tokyo Japanese and Montreal French, and Figure 1 shows some spectrograms of examples from Korean.

Descriptions of devocalization in Montreal French often class it together with the alternations involving [ə] that occur even in the European dialects - e.g., standard Parisian [apastam a] [аравtmã] for appartement 'apartment', [pati] [pti] for petit 'small (m)', or [damãdare] [dmãdse] for demanderai 'ask (1 s, fut)' (see Delattre 1951, and Verluyten 1988, inter alia for the "schwa-deletion" of European French, and Cedergren and Simoneau 1985, for the Montreal French processes). Most traditional descriptions of devocalization in Japanese, by contrast, have not equated it with the English and German schwa-deletion described in the previous section, perhaps because there is a more intuitive phonological analysis. That is, in the most typical environment for the phenomenon - a short high vowel between voiceless consonants - the usual transcriptions make it look like an assimilation of [+voice] to [-voice] in a [-voice] context. If one assumes the phenomenon to be a phonological process, such an assimilatory change is a more natural phonological rule than one that deletes high vowels between voiceless consonants. Another advantage of the devoicing analysis is that it correctly predicts that, when the process occurs between identical preceding and following consonant onsets, there is no neutralization with the corresponding geminate, a fact which must be stipulated separately in a deletion account. That is, "deleting" the medial vowel in /sjokikan/ [jok(i)kan] '(cabinet) secretary' does not yield a homophone for /sjokkan/ [jok:as] 'tactile organ' because the first $/ \mathrm{N} /$ is still released.

Table 3. Devocalization in Tokyo Japanese and in Montreal French.

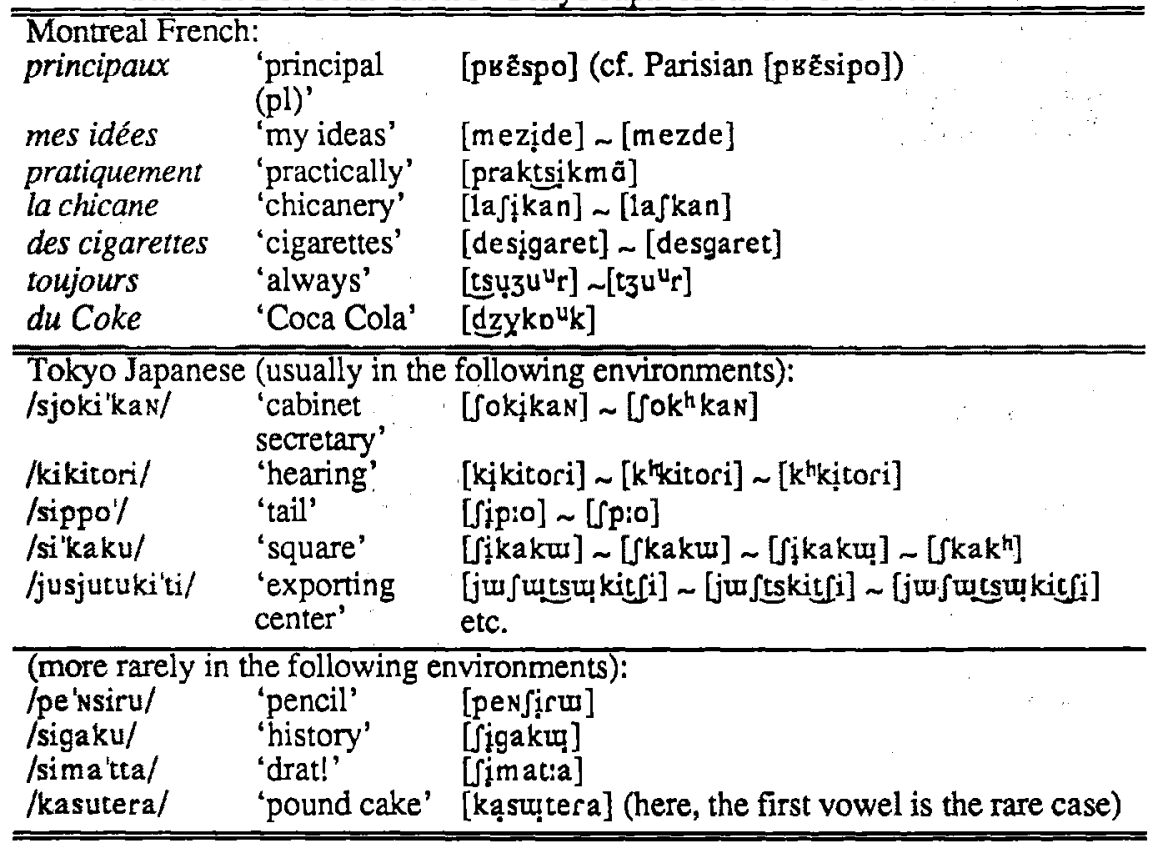

However, there are two aspects of devocalization in all three of these languages that suggest that the same general phonetic mechanism is at work as in German and English "schwa deletion". First, the phenomenon seems to apply "gradiently", 
(a)

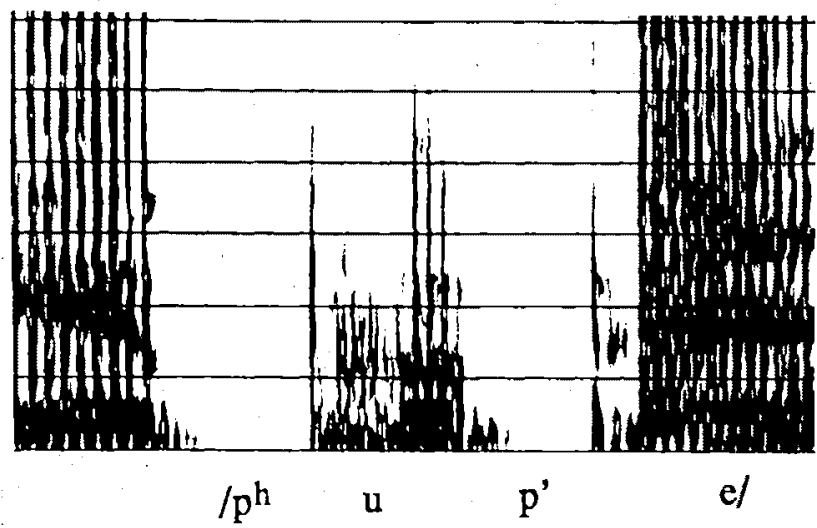

(b)
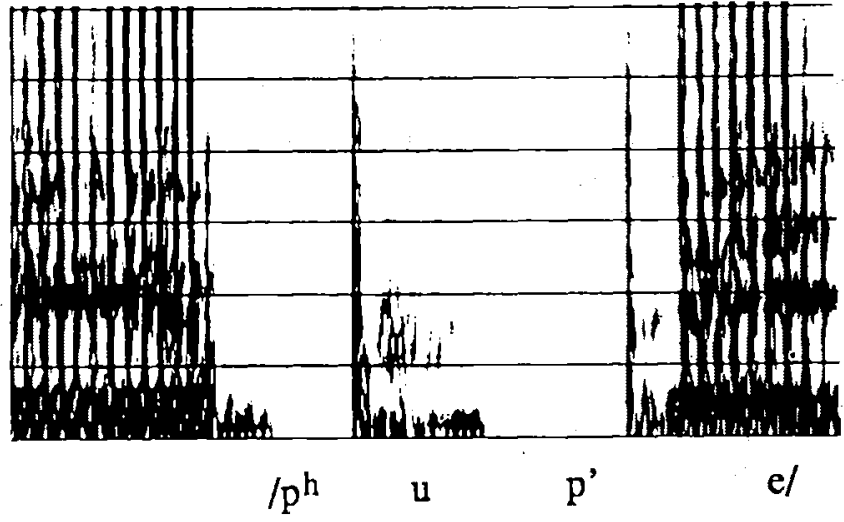

(c)

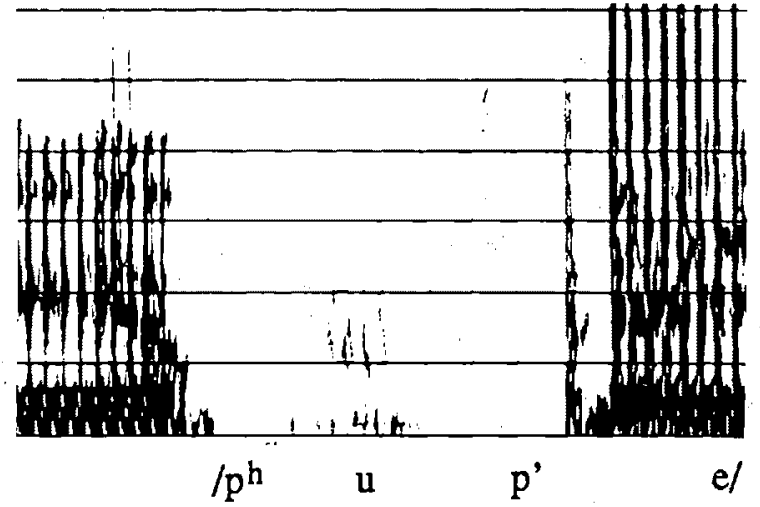

Figure 1. Tokens of Korean / $\mathrm{p}^{\mathrm{h}}$ up' $\mathrm{e}$ / 'unripe pear' showing (a) "voiced", (b) "partially devoiced" and (c) "completely devoiced" types for the / $\mathrm{u} /$ in the target first syllable. The preceding context is an /e/. From Jun \& Beckman (1993). 
creating tokens with varying degrees of devocalization even for the same input type. For example, in their study of Montreal French high vowels, Cedergren and Simoneau (1985) could distinguish among mere "reduction" (a very short vowel less than $30 \mathrm{~ms}$ - but nonetheless showing some periodic energy at the second formant), "devoicing" (a somewhat shorter vowel showing only aperiodic noise excitation), and "true syncope". A similar gradation can be seen in the Korean examples in Figure 1, which illustrates the three-way classification used in Jun and Beckman (1993). We called a vowel "voiced" only when the periodic energy from the laryngeal source was large enough for a long enough interval to visibly excite the second or higher formants on the spectrogram. In addition to "completely devoiced" tokens, this criterion excluded many tokens where there were one or two weak glottal pulses visible at the bottom of the spectrograph, tokens which we called "partially devoiced". For Japanese, Maekawa (1990) used similar criteria to differentiate two possible grades of "devoicing", whereas Beckman and Shoji (1984) and Kondo (1993), while noting the gradient nature of the phenomenon, make only a two-way distinction between "voiced" (showing at least one glottal pulse) and "fully voiceless" (for Kondo) or "deleted" (for Beckman and Shoji). It is probably this gradation in part that gives rise to the vacillation in the phonological literature between the more common traditional "devoicing" analyses (e.g., Bloch's 1950 transcriptions for stop-initial syllables, Shibata 1955, McCawley 1968) and the less usual "deletion" analyses (e.g., Bloch's 1950 transcriptions for many affricate- and fricative-initial syllables, Ohso 1973).

Beckman and Shoji (1984) highlight another way in which the phenomenon is "gradient" - the patterns of neutralization that are observed. We presented minimal pairs of words with "fully devoiced" /si/ versus /sju/ syllables to subjects for identification, and found neither the reasonably good recognition one would expect for a true voiceless vowel $\left([j i] \neq\left[\int u \underline{]}\right]\right)$ nor the categorical neutralization one would expect if the vowel were phonologically deleted (/si/ $\rightarrow[\delta]=\left[\int\right] \leftarrow /$ sju/). Rather, listener identifications showed a continuum of degrees of confusion between the two candidate words, and a strong correlation between the percentage of correct responses for a token and the degree to which the fricative's spectrum in the token was colored by the underlying vowel. As Jun and Beckman (1993) point out, an analysis that takes the process out of the phonology and represents it instead in terms of variable degrees of overlap in the gestural score would capture both the spectral and perceptual gradation in the signal.

The second aspect of the phenomenon that supports the gestural-score representation is that it occurs to varying extent for different segmental sequences and in different prosodic positions. For example, Cedergren and Simoneau (1985) and earlier studies of devocalization in Montreal French found that it does not occur in rhythm-group final syllables, where the vowel is prosodically lengthened and less likely to be completely covered over by the neighboring consonants' gestures (see, e.g., Levac, Cedergren \& Perreault 1993 for evidence concerning rhythmgroup final lengthening in Montreal French). In Japanese, similarly, devocalization is limited to phonemically short vowels, and it most commonly affects the two high vowels, which are phonetically very short even when they are not devocalized. Devocalization does occur sometimes with mid and low vowels (see, e.g., Kondo 1993, Maekawa 1990), but here it is relatively rarer. The NHK (1985) pronunciation dictionary singles out particularly the syllable types $/ \mathrm{ka} /, / \mathrm{ko} /, / \mathrm{ha} /$, and $/ \mathrm{ho} /$ in word-initial unaccented position, where the consonant is most strongly aspirated. For either high or nonhigh vowels, devocalization is also most common between voiceless consonants, where the vowel's glottal gesture is subject to overlap from devoicing gestures on both sides. Indeed, for high vowels in this context, devocalization is quite common even in the most careful read speech. For 
example, Takeda and Kuwabara (1987) found in their analysis of a large database of citation-form productions by a professional announcer that $90 \%$ of the /si/ syllables before voiceless consonants were devocalized (see also Kondo 1993).

Since Korean contrasts three types of voiceless stops and affricates, an even finer analysis of the effect of consonantal context is possible. If the gestural overlap account is correct, devocalization should be most likely to occur after an aspirated stop, where the glottal-opening gesture is largest and extends well past the oral release, and it should be least likely to occur after a fortis stop, where the glottal-opening gesture is abruptly terminated by a tense glottal adduction just before the oral release (Kagaya 1974; Hirose, Lee, \& Ushijima 1974). Comparing different prosodic positions, we can also predict that devocalization should be more common at the beginning of an accentual phrase, where aspiration is longer in an aspirated stop (Jun 1990a) and the voicing from the preceding vowel is less likely to continue well into the closure for a lenis stop (Jun 1990b, 1993; Silva 1992). These predictions were borne out in our recent study of productions by three Seoul and three Chonnam speakers' productions (see Figure 2).

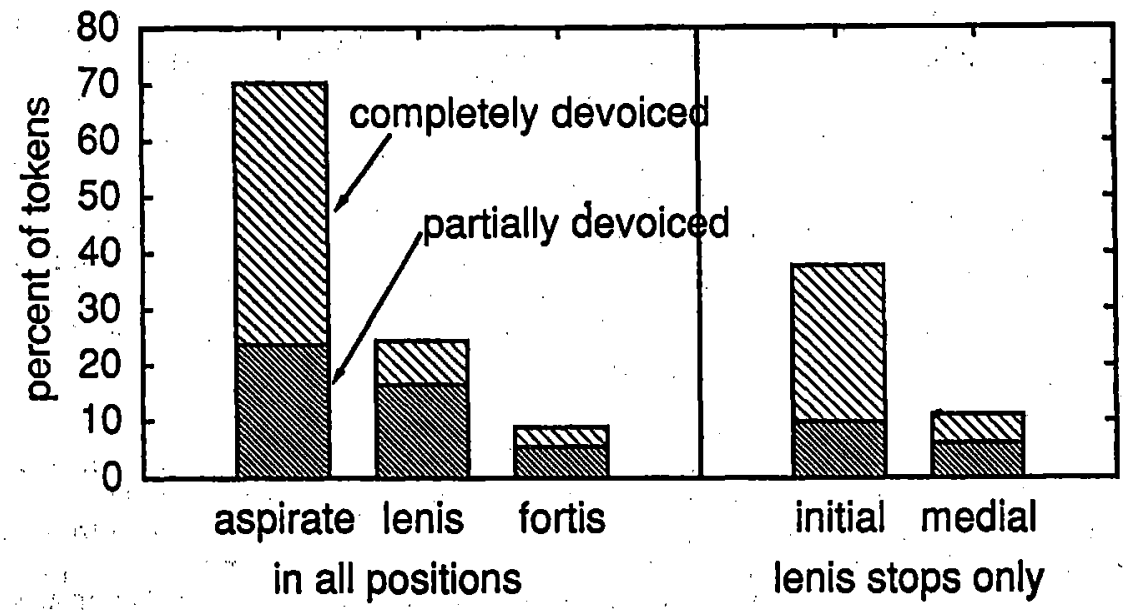

Figure 2. Distribution of "partially devoiced" and "completely devoiced" tokens after different types of preceding consonants (left), and for the vowels after lenis stops in different prosodic positions (right). From Jun \& Beckman (1993).

If devocalization is an artifact of overlap and encroachment by the gestures of an adjacent consonant, we might also predict a sequence of a voiceless fricative or affricate consonant followed by high vowel to be a particularly likely environment for the effect. The prediction stems from the observation that articulatory movements into and out of a fricative constriction are often slower than movements into and out of a homorganic stop closure (Kuehn \& Moll 1976). When an oral constriction that is narrow enough to give rise to frication is slowly released into the only somewhat less constricted oral configuration for a short high vowel, the oral air pressure that has built up behind the constriction cannot be vented as rapidly as it can when the consonant is a stop or when the release is into a more open vowel. Well into the vowel, aerodynamic conditions may remain more conducive to continued turbulence at the oral constriction than to vocal fold vibration, and if the vowel is short enough, it can be effectively devoiced or deleted. The prediction of greater frequency of devocalization after fricatives and affricates is borne out in Takeda and Kuwabara's (1987) and Kondo's (1993) data for Japanese, in Jun and 
Beckman's (1993) data for Korean, and in Cedergren and Simoneau's (1985) data for Montreal French.

In sum, there is a wealth of literature documenting the continuously variable nature of devocalization in Japanese, Korean, and French, and the variable extent to which it occurs in different segmental environments. Both these aspects of the phenomenon strongly suggest that devocalization should be represented as the consequence of more or less subtle changes in the phonetic specification of gestural magnitude and intergestural timing in an otherwise invariant gestural score, an analysis that is essentially identical to the account presented in Section 2 for apparent schwa deletion in English and German. Thus, the two phenomena schwa deletion and high-vowel devocalization - can both be described as gradient phonetic reductions, presenting comparable difficulties for analyses that posit disparate synchronic phonological rules to categorically delete the segment or to categorically change the vowel's voicing features.

\section{The potential for prosodic reanalysis}

On the other hand, when viewed over longer intervals of time, such phonetic reductions can lead to categorical changes, sometimes resulting in alternations that can be described better by synchronic phonological rules. Following Ohala (1974, 1981), we can think of sound change as a grammatical reanalysis that originates in a listener's misinterpretations of the speaker's underlying phonological intent - in this case in a misinterpretation or reanalysis of the intended prosodic structure. For example, the Modern English regular -s plural shows an alternation between a syllabic / $/ 2 /$ and a nonsyllabic /s/ or /z/, the latter apparently due to a prosodic reanalysis of consonantal overlap and consequent vowel reduction in the unstressed final syllable of Old English forms such as stanas 'stones' and munecas 'monks' (Beckman, de Jong, Jun \& Lee 1992). Similarly, the modem Tokyo Japanese /t/final verb paradigms and compound words in Table 4 show an alternation between single and geminate consonant - that is, between two short open syllables and a long closed syllable - an alternation that, in the $/ t /$-final verb paradigms at least, must have resulted from a prosodic reanalysis of a devocalized high vowel in an earlier stage of the dialect. (For an alternative hypothesis concerning the history of the alternation in the Sino-Japanese compounds with / $/$, see Itô \& Mester 1993.)

Table 4. Standard Japanese alternations with /t:/ and / $\mathrm{k:} /$.

\begin{tabular}{|c|c|c|c|}
\hline verb stems & non-past & past & Sino-Japanese compounds with /k:/ \\
\hline /kat/'win' & /ka.tu/ & {$[$ kat:a] $(=/$ kat.ta $/)$} & \\
\hline /mat/ 'wait' & Ima.tl & & Lga \\
\hline $\begin{array}{l}\text { /ut/ 'beat' } \\
\text { cf /kas/ 'lend' }\end{array}$ & $\begin{array}{l}\text { /u.tu/ } \\
/ \mathrm{ka} . \mathrm{su} /\end{array}$ & $\begin{array}{l}{[\text { wt:a }](=/ \text { ut.ta/) }} \\
{[\text { kajta] }(=/ \text { ka.si.ta) }}\end{array}$ & $\begin{array}{l}\text { /koku/ 'country' + /ka/ 'house' - } \\
\text { [kok:a] (= /kok.ka/ 'nation' }\end{array}$ \\
\hline
\end{tabular}

Given that small phonetic shifts in gestural organization can lead diachronically to phonological reanalysis and sound change, we should not be surprised to see evidence that reanalysis of forms that are habitually subject to vowel reduction has occurred in some cases even in contemporary grammars. And, indeed; there is such evidence. Zwicky (1972, p.283) notes that for him the fast-speech schwadeletion rule "Slur" is "obligatory" in the second syllables of the words camera, every, celery, general, mystery, chocolate, and family. That is, productions of these forms with extreme encroachment by the surrounding consonants into the /a/ have been prosodically reanalyzed (or perhaps were originally misinterpreted in acquisition) as disyllables $/ \mathrm{kæm} . \mathrm{s} ə /, / \varepsilon v . \mathrm{ji} /, / \mathrm{s} \varepsilon 1 . \mathrm{si} /, / \mathrm{d} z \varepsilon n . \mathrm{s} ə 1 /$, and so on. Ramsaran, in the revised 4th edition of Gimson $(1989$, p. 1989) likewise says of 
British English forms such as /n'æt $\int \mathrm{sal} /$ for natural and /t'empsəsi/for temporary: "Though labelled here as 'colloquial' these elisions may occur regularly within the speech of an individual, the fuller form not forming part of his idiolect." Louise Levac (personal communication) states that devocalization has similarly led to a prosodic reanalysis of forms such as principaux, which for her and many other Montreal French speakers is a disyllable/prex.spo/ (and is transcribed as such in the prosodic transcription system' used for sociolinguistic databases at l'Université du Québec á Montréal - see Levac et al. 1993).

In still other cases, we see evidence of incipient reanalysis in speaker uncertainty or in vacillating judgments about syllable count. Thus, for example, Stefanie Jannedy (personal communication) states that for her, Kannen feels not quite disyllabic: "It's more like a syllable and a half." Moreover, her native speaker intuition about such forms varies from word to word. By contrast to Kannen, leiden is unquestionably two syllables, and beraten is unquestionably three. The discrepancy between her uncertainty about Kannen and certainty about beraten seems in keeping with the perception data noted above for productions by other northern German speakers (Jannedy 1993). More than half the tokens of Kannen were misperceived as kann by the majority of the listeners, whereas none of the tokens of beraten was misperceived as braten by more than $40 \%$ of the listeners. It seems that Kannen is closer than beraten is to a communal shift to becoming a homophone for the originally shorter word.

Zwicky (1972), too, describes a continuum from "obligatory" application of "Slur" in forms such as camera and every to complete failure to apply in forms such as graciously, Arabic, and element. That is, for him, [kæ.ma..ə] is at best a stilted

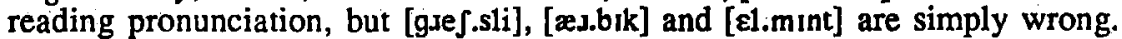
Louise Levac also says that in citation, which has the contrasting disyllabic station, the [st] sequence resulting from devocalization of the [i] is not reanalyzed as an onset cluster, 'and in careful lab speech [s.ta.sjō] has a somewhat longer [s] and thus is not categorically neutralized with [sta.sjö]. These examples suggest that, in German and English and Montreal French, reanalysis is available for some words, but not for all words in which reduction is possible.

In Japanese, on the other hand, prosodic reanalysis is unavailable across the board. Despite the examples of phonological alternation in forms such as /gaku/ in isolation versus /gak/ for the same morpheme in /gak:o:/, even the most drastic devocalization of the medial vowel in /sjokikaN/ " (cabinet) secretary' does not yield a homophone for /sjokias/ 'tactile organ'. That is, although the preceding and following consonants' glottal gestures usually overlap and blend together so thoroughly that no hint of a glottal adduction for the $/ \mathrm{i} /$ is present, the overlap of the consonant's oral gestures is never so great as to effectively delete the release of the first stop, even in cases such as /sjokikas/, where the resulting form would be phonotactically possible in the modern language.

Thus the reinterpretation of underlying prosodic structure is a natural but not a necessary endpoint for every continuum of gestural overlap. How, then, can we explain the variability? What are the conditions conducive to a prosodic reanalysis of syllables with extremely reduced vowels? Conversely, what factors seem to be correlated with a resistance to such a prosodic reanalysis? These questions seem worth pursuing not just for their own sake, but also for what they can tell us about the relationship between physical, phonetic structures such as stop releases and vowel formants, and such cognitive, phonological categories as the syllable.

\section{Phonotactic constraints on the shape of the syllable}

The factor that will be examined at most length in the rest of this paper has already been suggested. Prosodic reanalysis should be difficult, if not impossible, whenever the result would be a consonant cluster or a syllable type that is rare or 
unattested in the rest of the lexicon. This seems to be the primary consideration blocking reanalysis of forms with devocalized vowels in Modern Japanese. The language has only one type of tautosyllabic cluster: onset clusters with $/ \mathrm{j} /$, as in /kjaku/ 'visitor'. It has only three types of closed syllable: those that end in the first mora of a geminate consonant, as in /kok.ka/ 'nation'; those that end in the moraic nasal / $/$, as in /kon.ki/ 'endurance'; and those very rare overlong syllables that end in both, as in /ron.donk.ko/ 'Londoner'. Thus, except for the sequences of two like consonants that constitute geminates and the sequences of moraic nasal and following consonant in words such as / konki/ and /ron.donk.ko/, there are no heterosyllabic phonological consonant clusters in the language. Therefore, if reanalysis of words with devocalized vowels is limited to forms that result in legitimate consonant clusters, then it cannot apply in the overwhelming majority of cases. Reanalysis would not be available for the devocalized vowels in [kikitori] 'hearing', [suppo:tu] 'sports', and [jjkaku] 'square' because /kk/,/sp/ and /sk/ are not possible onsets. It would not be available for [kajita] 'lent' and the second vowel in [kikitori] because /st/ and / $\mathrm{kt} /$ are not possible consonant sequences even across a word-medial syllable boundary. The only cases where reanalysis would be possible in principle are those where the devocalized vowel happens to come between two like obstruents within a word - e.g., /sjokikan/ cited above, or /kasisitu/ [kafifitsur] 'rented room'. As was also noted above, however, even these cases are not reanalyzed in modern Tokyo Japanese, and native speakers take care to audibly release the first consonant in stop-stop sequences, apparently to preserve the syllable count. It is noteworthy that it is the syllable count that matters here, since mora count would be preserved even if the consonant were reanalyzed as the coda half of a geminate. This offers further support to Kubozono's (1989, forthcoming) claim that the syllable is a psychologically real unit above the mora in Japanese.

In Korean as well, very similar phonotactic constraints on consonant sequences and syllable structure conspire against reanalysis. Like Japanese, Korean has no tautosyllabic clusters other than consonants followed by glides in the onset, as in /kwa/ 'and' and /kjalhon/ 'marriage'. Therefore, the only potential reanalysis is in a $\mathrm{C}_{1} \mathrm{~V}_{1} \mathrm{C}_{2} \mathrm{~V}_{2} \mathrm{C}_{3} \mathrm{~V}_{3}$ sequence when $\mathrm{V}_{2}$ is devocalized and $\mathrm{C}_{2}$ could, in theory, be reinterpreted as a coda consonant to yield a phonotactically possible heterosyllabic cluster with $\mathrm{C}_{3}$. Although Korean has far more closed syllables and more types of medial consonant cluster than does Japanese, the restrictions on heterosyllabic obstruent-obstruent sequences are still quite extensive by comparison to English, German, or Montreal French. The only obstruent type that is allowed in coda position is an unreleased lenis stop. When an underlying morpheme-final fricative or affricate or a fortis or aspirated stop occurs in a position where it cannot be resyllabified with a following vowel - i.e., when it is phrase-final or when the following morpheme begins with any consonant other than a glide - it surfaces as the homorganic lenis stop, as shown in the examples in Table 5. Thus, the only type of $\mathrm{C}_{1} \mathrm{~V}_{1} \mathrm{C}_{2} \mathrm{~V}_{2} \mathrm{C}_{3} \mathrm{~V}_{3}$ sequence where reanalysis alone would yield a phonotactically permissible coda is one where $C_{2}$ is a lenis $/ \mathrm{p} /, / \mathrm{t} /$, or $/ \mathrm{k} /$. However, this is exactly the context where a lenis stop would be voiced, making it unlikely that $\mathrm{V}_{2}$ would undergo devocalization. On the other hand, coda stops are also always unreleased. Therefore, the overlap on the oral tier must be extreme enough so that the closure for $\mathrm{C}_{3}$ can hide the aerodynamic consequence of releasing $\mathrm{C}_{2}$, and such extreme overlap could conceivably result in reanalysis even when $C_{2}$ is an underlying fortis or aspirated stop. However, as in Japanese, complete overlap in devocalization seems to be limited to the glottal tier, and syllable count is maintained in the face of devocalization. 
Table 5. Coda neutralization in Korean.

\begin{tabular}{|c|c|}
\hline \multicolumn{2}{|c|}{ /təs/ 'cover' +/posən/ 'cloth socks' $\rightarrow$ /tat.p'o.san/ "(traditional cloth) slippers' } \\
\hline /path/ 'aduki bean' + /komul/ 'flour' $\rightarrow$ /pat.k'o.mul/ 'aduki bean $f$ & \\
\hline 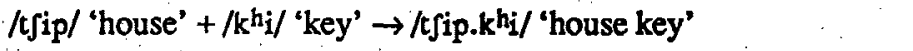 & \\
\hline /nat $/$ 'to be low' + /ta/ non-past tense marker $\rightarrow /$ nat.t'a/ is low' & \\
\hline
\end{tabular}

Adherence to otherwise unviolated phonotactic constraints is also an important factor in determining the syllable count for several of the English and German forms in Table 1. For example, reanalysis and loss of a syllable is precluded in [tl'iro] for Toledo and [ $\mathrm{Smp}^{\mathrm{h}}$ anza] for Schimpanse, where it would yield illegal onset clusters $/ \mathrm{tl} /$ and $/ \mathrm{smp} /$. It is also precluded in [ $\mathrm{p}^{\mathrm{h}} \mathrm{Am}$ ] pommel and [1ardn] leiden, where it would yield illegal coda clusters $/ \mathrm{ml} /$ and $/ \mathrm{dn} /$. That it is phonotactic constraints related to syllable position at work here is clear when we contrast the latter two forms to words such as family and geladene. In these originally three- or four-syllable forms, the same $/ \mathrm{ml} /$ and $/ \mathrm{dn} /$ sequences would result from reanalysis, but because the reduced vowels are in medial syllables in these cases, the consonants can be differentially assigned to the preceding and following syllables to make legal coda and onset. In these forms, reanalysis seems more possible, and indeed Zwicky (1972, p. 283) lists family as an example of "obligatory" application of his schwa-deleting rule.

However, the standard view of phonotactic constraints cannot explain all cases where reanalysis seems difficult. Reinterpreting Arabic and element as disyllabic /'æi.bık/ and /el.mint/ gives consonant sequences that are actually attested in the words barber and Elmer, yet Zwicky (1972) rules out even the application of the fast-speech reduction rule in these forms. He cites Arabic and element, along with graciously, relevant, and many others, as evidence that, unlike the rule of "Prestress Contraction" that gives rise to [vs'niri] for vicinity, "the deletion in Slur is not governed by any simple or obvious conditions on the 'pronounceability' of the result" (Zwicky 1972, p. 283). To account for these patterns, Zwicky posits a continuum of acceptability, with values based on the type of consonant following the reduced vowel, according the ranking:

$[\mathrm{j}]>[1]>[\mathrm{n}]>[\mathrm{m}]>[\mathrm{g}]>$ fricatives $>$ stops where " $>$ " should be read as "is better than". That is, the output of the schwadeletion rule is more acceptable (or the rule can be applied in a higher proportion of words) in which the following environment is an [s] than in words where an [1] follows, and so on. (Most of the forms where the rule is "obligatory" for Zwicky in fact are forms with following [3], and Gimson 1989, pp. 238-239, gives more examples with [ $\mathrm{s}]$ and $[\mathrm{l}]$ than [n] or any other following consonant.)

My own intuitions accord with the notion that there is a continuum of acceptability governing both the likelihood of reanalysis and the degree of reduction that is tolerated, although I would emphasize also other things in the ranking. Zwicky himself lists two other things. Reanalysis seems considerably less likely if the following syllable has secondary stress (as in the verb degenerate [didz'znaj,et] versus the adjective [didz' $\varepsilon$ nat]), or if the target vowel is in a closed syllable (as in development or honestly).

The first of these factors might be related to the ways in which prosodic structure is realized in the gestural score. For example, when the following consonant begins a stressed syllable, there is probably less overlap between it and the target vowel. Evidence for this lesser overlap can be seen in the greater coarticulation of an unstressed syllable with a preceding stressed syllable than with a following (e.g. 
Fowler 1981) and the lack of a durational effect of voicing of the following consonant when the target vowel is reduced (Davis \& Summers 19.89).

I think the second factor has to do not so much with the mere fact of a cluster following the target vowel as it does with the phonological complexity or awkwardness of the resulting coda or onset; and I would also include the sonority difference between the flanking consonants as a possibly independent factor influencing the relative awkwardness. Thus, disyllabic Arabic (with a heterosyllabic sonorant-obstruent sequence $/ \mathrm{s} . \mathrm{b} / \mathrm{h}$ seems a more plausible phonological interpretation than disyllabic element (with its two sonorant consonants $/ \mathrm{l} . \mathrm{m} /$ ), which in turn is far more plausible than disyllabic honestly (with its more complex coda cluster /nst.l/) or disyllabic graciously (with its tonguetwister sequence of postalveolar and alveolar fricatives $/ \int . s 1 /$.

To be sure, more than complexity or awkwardness might be involved in honestly, since /t/ cannot be in the onset of a following syllable with $/ / /$ and $/ n s t /$ is not an attested coda word internally. (It is arguably not even an attested coda wordfinally, since coronals in forms such as in minced have been claimed to be affixes outside of the syllable core - see, e.g., Fujimura 1979.) However, none of the other cases cited here involves a clearly phonological restriction against the resulting consonant cluster: $/ \mathrm{J} /, \mathrm{N} /$; and $/ \mathrm{s} /$ are all attested post-vocalic strings in English, and $/ \mathrm{b} /, / \mathrm{m} /$, and $/ \mathrm{s} 1 /$ are all attested onsets.

At the same time, it is not clear to me that these factors can be so easily distinguished from the considerations that preclude reanalysis in Toledo or pommel, or in the majority of Japanese and Korean cases cited earlier. The distinction between phonological and phonetic factors hinges crucially on a very rule-like conception of phonotactics (and of morpheme-structure constraints in general), a conception whereby a grammar either has a particular constraint or it does not. It might be fruitful to pursue alternative models of phonology in which traditional phonotactic constraints are only an extreme example of speakers' knowledge of the relative frequencies of sequences and structures in the lexicon (see Pisoni, Nusbaum, Luce, \& Slowiaczek 1985; Pierrehumbert in press). That is, for an English speaker, the awkwardness of $/ \mathrm{l} . \mathrm{m} /$ and the unacceptability of $/ \mathrm{nst} .1 /$ wordmedially might differ from the illegality of $/ \mathrm{t} 1 /$ word-initially not in kind but in degree: a low probability of occurrence versus zero or near-zero probability. In such a model the fact that reanalysis of a reduced vowel is impossible for [tilido] Toledo and possibly for [ร'onstli] honestly but merely quite unlikely for ['Elmint] element would not be two disparate facts to be represented by two different devices, but merely two points along the same scale.

Such a conception of phonotactic constraints might also offer a better understanding of the Japanese case, where a consonant preceding a devocalized vowel remains an onset even when reanalysis as a coda consonant would yield a phonotactically legal heterosyllabic consonant cluster. As Kubozono (1993) points out, the vast majority of syllables in Modern Japanese are open. Although closed syllables are phonotactically legal, they are comparatively rare. Reanalyzing the consonant in the second syllable of a form such as [ka.f. fi.tsur] or [jo.k(i).kas] as a coda for a long syllable rather than as an onset for a short syllable may be unacceptable for a lesser degree of the same reason that reanalyzing the second consonant in [ka jita] as a coda is impossible. The analogous account should work for the Korean facts as well.

The distribution of "true syncope".in Montreal French, on the other hand, may remain difficult even within this framework. Phonotactic constraints on syllable structure do seem to affect the likelihood of devocalization. Cedergren and Simoneau (1985) list the indicated vowels in [ob1(i)ze] obligé and [admin(i)stbasjã] administration as cases where syncope is highly unlikely, and an adjacent consonant cluster is one of the strongest negative factors in their Varbrul analysis of 
the frequency of occurrence of such completely elided vowels. If frequency of occurrence is related to likelihood of reanalysis, these facts would suggest that syncope is avoided where it would result in clusters such as [b13] and [nstr] that cannot be readily parsed in reanalysis. However, Cedergren and Simoneau also list among their examples of likely syncope not only forms such as [prezspo] for principaux, [televzjõ] for télévision, and [lynivesste] for l'université, where reanalysis would yield a perfectly legal consonant cluster, but also forms such as [pma] for pis ma, [vsave] for vous savez, and [tz" "r] for toujours, where an impossible syllable onset would result. Presumably, these forms are not as readily reanalyzed as principaux. Yet their Varbrul analysis showed "true syncope" to be slightly more likely to occur in the initial syllable of a rhythm group than in other non-final positions. Since this is a position where such impossible clusters are likely to result (as in the examples just cited of pis ma, vous savez, and toujours), perhaps the likelihood of phonological reanalysis and the frequency of occurrence of such extreme devocalization may not be so closely related as we would expect from our explanation of the relative infrequency of devocalization in vowels before consonant clusters. Or perhaps there is some other factor that works to obscure the relationship between phonotactic acceptability and devocalization rates when comparing vowels in different positions in the rhythm group.

\section{Some other factors}

The preceding section examined phonotactic constraints on the shapes of syllables as a factor in determining whether a form with a substantially reduced vowel is susceptible to phonological reanalysis as having no vowel underlyingly - i.e., as having no syllable nucleus in that position. The discussion at several points hinted at other factors that might also be at work in influencing whether reanalysis will occur. There is no space to pursue the question further in this paper, but $I$ can at least briefly mention three other factors that seem worth investigating in more detail.

The first factor is the existence of contrasting forms. This factor was already suggested in the observation that in Montreal French, citation [s.ta.sjō] seems to be immune to reanalysis because of the potential homophony with station [sta.sjō]. Similarly in German, Stefanie Jannedy (personal communication) says that reanalyzing geladene as three syllables is easier for her than reanalyzing Ebenen as two, because there is no contrasting form *geladne but Ebenen contrasts with the related verb ebnen 'to level, to smooth'. On the other hand, the resulting homophony does not seem to preclude reanalysis for Kannen. Thus, existence of contrasting forms may be a relatively weak consideration at best.

The second factor is clearly stronger. It is the influence of other levels of linguistic structure - of prosodic constituents above the syllable. In German and English, the crucial relevance of one higher-level constituent is obvious already in the definition of the reduction effect. "Schwa-deletion" cannot occur unless there is a $/ \mathrm{a} /$ - that is, it cannot occur in a syllable that is the head of stress foot. The different patterns of reanalysis seen in British and American English for words such as laboratory (three-syllable British [12b' $\partial^{\circ}$ tri] versus four-syllable American [1'æbJat,oxi]]) highlight the importance of this prosodic constituent. However, the unlikelihood of complete reduction of a stressed vowel is not the only aspect of foot structure that is relevant in determining when reanalysis can occur. In northern German dialects, it seems that reanalysis is also more difficult for a pre-tonic syllable than for a post-tonic syllable. Thus, extreme vowel reduction and consequent assimilation and simplification of the resulting [gn] sequence is quite likely in casual-speech productions of Wagen (see [v'a:gn] $\rightarrow$ [v'a:gn] $\rightarrow$ [v'a:n] in Table 2 above), but comparable reduction and simplification is impossible in gemütlich 'cozy' $\rightarrow{ }^{*}$ [gm'ytliç] $\rightarrow{ }^{*}$ [gg'ytliç] $\rightarrow *$ [g'ytliç]. The relevant fact here 
seems to be the foot affiliation of the consonants; the two consonants in the resulting /gn/ sequence in Wagen belong to the same foot, whereas in gemütlich the $\mathrm{g} /$ does not belongs to the foot that starts with the $/ \mathrm{m} /$. Here we can also contrast Sekunde /zek'Unda/ 'second' to subtil 'subtle'. In Stefanie Jannedy's Hamburg dialect Sekunde cannot lose its schwa to become *[sk'Unde], presumably because the $[\mathrm{k}]$ here is an onset consonant for the head of the stress foot, whereas the [p] in subtil is the coda for the pre-tonic syllable (as is clear from the devoicing of the original / $b /$ in the French loan source, which is still reflected in the orthography).

While the stress foot is quite obviously related to reduction and reanalysis in these two stress-timed languages, it is not the only potentially relevant prosodic unit cross-linguistically. As noted already in Section 5, the effects of position of the target syllable in the accentual phrase are particularly relevant for understanding why reanalysis does not occur for devocalized vowels in Korean. A post-lexical phonetic voicing of lenis stops that are medial to the accentual phrase removes the segmental environment for devocalization in just the position where reanalysis would yield a legal consonant coda. The homologous unit in Montreal French also strongly conditions the likelihood of vowel reduction. Again as noted already, devocalization does not occur at all in the last syllable of the rhythm group, and it is slightly more likely to occur in the first syllable than in other non-final syllables. It would be interesting to see whether initial syllables have the same advantage over medial syllables if penultimate syllables are excluded from the comparison. Levac et al. (1993) show that in Montreal French, the lengthening seen cross-dialectally in the last syllable of the rhythm group also stretches out the immediately preceding syllable, albeit to a somewhat lesser degree. That is, the lengthening at the end of this prosodic constituent in Montreal French is a true edge effect, comparable to the final lengthening in intonation phrases in English (e.g. Edwards, Beckman \& Fletcher 1991), and rather unlike the lengthening in the European dialects of French, where the longer final syllable seems instead to be the culmination of a rhythmic alternation involving a shorter penultimate syllable and a possibly longer phrase-initial syllable bearing an accent secondaire (see, e.g., Fletcher 1991).

This difference between Montreal French and Parisian French seems related to the third factor: the sociolinguistic significance of the reduction. If forms with extremely reduced vowels are associated with one particular dialect and not another, then all of the sociolinguistic considerations of the relationship between the two dialects come into play, and we might expect reanalysis to be generalized, in either of two ways. On the one hand, if extreme reduction is associated with a more standard dialect, we might expect the reduction to become phonologized as the standard spreads. That is, if the phenomenon is salient as a mark of a more prestigious dialect to speakers of a nonstandard dialect, they might abstract a categorical rule for deriving forms in the standard dialect from the homologous native forms. Alternatively, if extreme reduction is associated with a stigmatized regional or class dialect, then the phenomenon might again become phonologized as a categorical mark of familiarity and group solidarity. Either pattern leads to the same result: vowel reduction (or any other connected speech process) should become phonetically less variable when it acquires sociolinguistic significance in relationship to another community of speakers (cf. Nolan \& Kerswill 1990).

Something like this hypothesis of phonologization seems to be assumed in Cedergren and Simoneau's (1985) discussion of their initial Varbrul analysis of overall levels of devocalization in their Montreal French speakers. The analysis included such factors as the age, education, and sex of the speaker, and the speaker's level of participation in the "linguistic market" - i.e., whether the speaker's work required that he or she interact often with speakers using a less regionally marked variety of French (Sankoff \& Laberge 1978). The women overall had generally lower rates for each of the three grades of reduction than did 
the men. Their productions also showed a closer relationship with degree of participation in the linguistic market than to age, and a much more complex pattern of phonological conditioning. Cedergren and Simoneau interpret the comparatively simpler phonological conditioning for the men (and the stronger relationship to age) as indicating "un phénomène en début d'expansion", whereas "pour les femmes, le processus est plus avancé dans le temps et servirait plutôt de différenciateur social." (Cedergren \& Simoneau 1985, p. 76). If a more complex phonological conditioning means a phonetically more variable phenomenon, then this suggests that the phenomenon is more phonologized among younger male speakers for whom it is spreading as a mark of solidarity in opposition to "standard" French.

It would be interesting to see also whether solidarity and prestige can account for some of the patterns of variability in vowel reduction in German. As opposed to the more northern varieties reported in Kohler (1990) and Jannedy (1993), southern German dialects show much more wide-spread reduction in pre-tonic syllables. In replicating her earlier experiment, this time using Schwäbisch speakers, Stefanie Jannedy has got recordings of productions such as [kft'o:le] for gestohlen 'stole', [ $\mathrm{p} \mathrm{j}^{\prime} \mathrm{aft}$ ] for beschafft 'procure', and [kf'Besa] for gefressen 'eaten', even at normal rate. ${ }^{2}$ Has the pre-tonic reduction been reanalyzed as a phonological mark of solidarity for these southern speakers? Conversely, do northern speakers deliberately retain such pre-tonic syllables in order not to sound like southern speakers? Has devoicing become so ubiquitous in Tokyo Japanese because it is a mark of the prestigious standard? The fact that the national broadcasting corporation has twice updated its dictionary prescribing where to devoice (NHK 1985) would suggest some such sociolinguistic significance. Conversely, my impression is that Kyoto and Osaka speakers very deliberately voice the vowels in the polite adjectival and verbal endings-desu and -masu when excluding speakers of the standard language.

The five languages briefly reviewed in this paper seem fruitful ground for investigating the many questions that become thinkable when we adopt an account of vowel reduction that represents it originally as the aerodynamic consequence of overlap in the gestural score, with potential phonological reanalysis for forms in which extreme overlap is a habitual pattern for some prosodic context or some group of speakers.

\section{References}

Beckman, M.E., de Jong, K., Jun, S.-A., \& Lee, S. (1992). The interaction of coarticulation and prosody in sound change. Language and Speech 35, 45-58.

Beckman, M., \& Shoji, A. (1984) Spectral and perceptual evidence for CV coarticulation in devoiced/si/ and /syu/ in Japanese. Phonetica 41, 61-71.

Bloch, B. (1950) Studies in colloquial Japanese IV: Phonemics. Language 26, 86125 .

Browman, C. P., \& Goldstein, L. (1990a) Tiers in articulatory phonology, with some implications for casual speech. In J. Kingston \& M. E. Beckman, eds.,

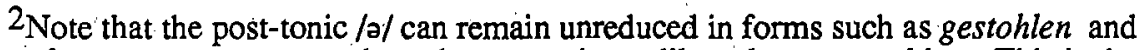
gefressen even at rates where the pre-tonic readily reduces to nothing. This is the opposite pattern from the analogous forms in northern German, where the pre-tonic syllable in, say, geleiten cannot be reduced unless the post-tonic is reduced at least to the same extent. Presumably the difference is related to the dialectal deletion of the final $/ \mathrm{n} /$ in gestohlen and gefressen, since in northern German forms such as gerade 'just', where there is no coda consonant in the post-tonic syllable, the facts are similar to those in southern German. 
Papers in Laboratory Phonology I: Between the Grammar and Physics of Speech, pp. 341-376. Cambridge: Cambridge University Press.

Browman, C. P., \& Goldstein, L. (1990b) Gestural specification using dynamically-defined articulatory structures. Journal of Phonetics 18, 299-320.

Cedergren, H. J., \& Simoneau, L. (1985) La chute des voyelles hautes en français de Montréal: "As-tu entendu la belle syncope?" In M. Lemieux \& H. J. Cedergren (eds.) Les tendences dynamiques du français parlé á Montréal, pp. 57-144. Montreal: Office de la langue française.

Davis, S., \& Summers, V. W. (1989) Vowel length and closure duration in wordmedial VC sequences. Journal of the Acoustical Society of America 85, S28.

Delattre, P. (1951) Le jeu de l'E instable intérireur en Français. French Review 24, 341-351.

Edwards; J., Beckman, M. E., \& Fletcher, J. (1991) Articulatory kinematics of final lengthening. Journal of the Acoustical Society of America 89, 369-382.

Fletcher, J. (1991) Rhythm and final lengthening in French. Journal of Phonetics 19, 193-212.

Fokes, J., \& Bond, Z. S. (1993) The elusive/illusive syllable. Phonetica 50, 102123.

Fowler, C. A. (1981) A relationship between coarticulation and compensatory shortening. Phonetica 38, 35-50.

Fujimura, O. (1979) An analysis of English syllables as cores and affixes. Zeitschrift für Phonetik, Sprachwissenschaft und Kommunikationsforschung 32, 471-476.

Gimson, A. C. (1989) An Introduction to the Pronunciation of English (4th ed., rev. by S. Ramsaran). London: Edward Arnold.

Hall, T. A. (1992) Syllable Structure and Syllable-related Processes in German. Linguistische Arbeiten 276, Tübingen: Max Niemeyer Verlag.

Hirose, H., Lee, C. Y., \& Ushijima, T. (1974) Laryngeal control in Korean stop production. Journal of Phonetics 2, 145-152.

Itô, J., \& Mester, A. (1993) Stem and word in Sino-Japanese: a case study in syllable optimization and alignment. Paper presented at the Dokkyo International Forum on Speech Recognition and Phonology, Dokkyo University, Soka City, Saitama Prefecture, 18-19 December 1993.

Jannedy, S. (1993) Rate effects on German unstressed syllables. Colloquium paper; Department of Linguistics, Ohio State University.

Jun, S.-A. (1990a) The domains of laryngeal feature lenition effects in Chonnam Korean. Journal of the Acoustical Society of America 87, S123.

Jun, S.-A. (1990b) The prosodic structure of Korean - in terms of voicing. In E.J. Baek (ed.) Proceedings of the Seventh International Conference on Korean Linguistics. Toronto: University of Toronto Press.

Jun, S:-A. (1993) The Phonetics and Phonology of Korean Prosody. Ph.D. dissertation, Department of Linguistics, Ohio State University.

Jun, S.-A., \& Beckman, M. E. (1993) A gestural-overlap analysis of vowel devoicing in Japanese and Korean. Paper presented at the 1993 Annual Meeting of the Linguistic Society of America, 7-10 January 1993, Los Angeles, CA, USA.

Kagaya, R. (1974) A fiberscopic and acoustic study of the Korean stops, affricates and fricatives. Journal of Phonetics 2, 161-181.

Kohler, K. (1990) Segmental reduction in connected speech in German: phonological facts and phonetic explanations. In W. J. Hardcastle \& A. Marchal, eds., Speech Production and Speech Modelling, pp. 69-92. Amsterdam: Kluwer. 
Kondo, M. (1993): The effect of blocking factors and constraints on consecutive vowel devoicing in Standard Japanese. Poster presented at the Fourth Conference on Laboratory Phonology, Oxford, 11-14 August 1993.

Kubono; H. (1989) The mora and syllable structure in Japanese: evidence from speech errors. Language and Speech 32, 249-278.

Kubozono, H. (1993). Perceptual evidence for the mora in Japanese. Paper presented at the Fourth Conference on Laboratory Phonology, Oxford, 11-14 August 1993.

Kubozono, H. (forthcoming) The syllable in Japanese. Submitted to Language.

Kuehn, D. P., \& Moll, K. L. (1976). A cineradiographic study of VC and CV articulatory velocities. Journal of Phonetics 4, 303-320.

Levac, L., Cedergren, H. J., \& Perreault, H. (1993) Phonetic evidence of narrow and wide temporal scope for prosodic constituents in French. In D. House \& P. Touati (eds.) Proceedings of an ESCA Workshop on Prosdy [Working Papers, Department of Linguistics and Phonetics, Lund, No. 41], pp. 54-57.

McCawley, J. D. (1968) The Phonological Component of a Grammar of Japanese. The Hague: Mouton.

Maekawa, K. (1990) Hatsuwa sokudo ni yoru yuusei kukan no hendoo [Effects of speaking rate on the voicing variation in Japanese]. Technical Report SP89-148, Densi Zyoohoo Tuusin Gakkai.

Manuel, S. Y., Shattuck-Hufnagel, S., Huffman, M., Stevens, K. N., Carlson, R., \& Hunnicutt, S. (1992) Studies of vowel and consonant reduction. Proceedings of the 1992 International Conference on Spoken Language Processing, vol. 2, pp. 943-946.

Nihon Hoosoo Kyookai (1985) Nihongo hatuon akusento jiten [Dictionary of Japanese Pronunciation and Accent Patterns], rev. ed. Tokyo: Nihon Hoosoo Shuppan Kyookai.

Nolan, F., \& Kerswill, P. E. (1990) The description of connected speech processes. In S. Ramsaran (ed.) Studies in the Pronunciation of. English: a Commemorative Volume in Honour of A. C. Gimson, pp.295-316. Padstow, Cornwall: T. J. Press, Ltd.

Ohala, J. J. (1974) Experimental historical phonology. In J. M. Anderson \& C. Jones (eds.) Historical Linguistics II: Theory and Description in Phonology, pp. 353-389. Amsterdam: North-Holland.

Ohala, J. J. (1981) The listener as a source of sound change. In C. S. Masek, R. A. Hendrick, \& M. F. Miller (eds.) Papers from the Parassession on Language and Behavior, pp. 178-203. Chicago: Chicago Linguistic Society.

Ohso, M. (1973) A phonological study of some English loan words in Japanese. Ohio State University Working Papers in Linguistics 14, 1-26.

Pierrehumbert, J. (in press) Syllable structure and word structure: a study of triconsonantal clusters in English. In P. A. Keating (ed.) Phonological Structure and Phonetic Form: Papers in Laboratory Phonology 3. Cambridge: Cambridge University Press.

Pisoni, D. B., Nusbaum, H. C., Luce, P. A., \& Slowiaczek, L. M. (1985) Speech perception, word recognition and the structure of the lexicon. Speech Communication 4, 75-95.

Price, P. J: (1980) Sonority and syllabicity. Phonetica 37, 327-343.

Sankoff, D. \& Laberge, S. (1978) The linguistic market and the statistical explanation of variability. In D. Sankoff (ed.) Linguistic Variation: Models and Methods, pp. 227-238. New York: Academic Press.

Shibata, T. (1955) Museika [Devoicing]. In Kokugogaku jiten [Dictionary of Japanese Language Studies], p. 899. Tokyo: Kokugogaku Gakkai.

Silva, D. J. (1992) The Phonetics and Phonology of Stop Lenition in Korean, Ph. D. dissertation, Department of Linguistics, Comell University. 
Strauss, S. L. (1982) Lexicalist Phonology of English and German. Dordrecht: Foris.

Takeda, K., \& Kuwabara, H. (1987) Boin museika no yooin bunseki to yosoku syuhoo no kentoo [Analysis and prediction of devocalizing phenomena]. Nihon Onkyoo Gakkai Kooen Ronbunshu [Proceedings of the Acoustical Society of Japan] 3-3-8, 105-106.

Verluyten, S. P., ed. (1988) La phonologie du schwa français. Linguisticae Investigationes Supplement . Amsterdam: John Benjamins.

Zwicky, A. M. (1972) Note on a phonological hierarchy in English. In R. Stockwell \& R. Macauley, eds., Linguistic Change and Generative Phonology, pp. 275-301. Bloomington, IN: Indiana University Press. 